\title{
Mutations of ousA Alter the Virulence of Erwinia chrysanthemi
}

\author{
Karine Gloux, ${ }^{1}$ Thierry Touze, ${ }^{2}$ Yves Pagot, ${ }^{3}$ Bernard Jouan, ${ }^{1}$ and Carlos Blanco ${ }^{2}$ \\ ${ }^{1}$ INRA, Unité Mixte de Recherche des Organismes et des Populations appliquée à la Protection des Plantes, Domaine de la \\ motte, B. P. 35327, 35653 Le Rheu Cedex, France; ${ }^{2}$ CNRS UMR 6026, Interactions Cellulaires et Moléculaires, Université \\ de Rennes I, 263 Av. du Général Leclerc, 35042 Rennes Cedex, France; ${ }^{3}$ Microbiologie et Génétique Moléculaire, UMR INA \\ P. G., INRA 1238 CNRS 2585, BP 01. 78850 Thiverval-Grignon, France
}

Submitted 28 June 2004. Accepted 18 October 2004.

\begin{abstract}
A negative correlation was observed between the aggressiveness of several Erwinia chrysanthemi strains on potato tuber and their osmotic tolerance. The disruption of the ous $A$ gene encoding the major osmoprotectant uptake system highly enhanced bacterial virulence on potato tubers. The ous $A$ disruption also increased the maceration efficiency on potato tubers under anaerobic conditions. In the absence of oxygen, pectate lyase (Pel) production was significantly higher in the tissue macerated with the ous $A^{-}$strain than with the wild type. Oxygen content is significantly different between infected and healthy tissues; therefore, ous $A$ may be a contributory factor in the infection progression within the host. In minimal medium, ous $A$ disruption enhanced Pel production and pelE expression only under micro-aerobiosis conditions. The effect on Pel was reversed by reintroduction of the ous $A$ gene. The osmoprotectectants glycine betaine, proline betaine, and pipecolic acid are known to be taken up via OusA and to have an inhibitory effect on Pel production. However, their effects on Pel activity were not (glycine betaine) or only weakly (proline and pipecolic acid) affected by ous $A$ disruption. Furthermore, no correlation was observed between their effects on Pel activities and their osmoprotection efficacies. The results demonstrate a relationship between $E$. chrysanthemi pathogenicity factors and the activity of ous $A$ under low oxygen status. The evidence indicates that ous $A$ and osmoprotectant effects on Pel are not linked to osmoregulation and that complex regulations exist between Pel production, ous $A$, and osmoprotection via compounds liberated during the plant infection.
\end{abstract}

Osmoprotectants are widely distributed compounds occurring in soil and plants (Rhodes and Hanson 1993; Rontein et al. 2002; Wyn Jones and Storey 1981). These solutes restore bacterial growth under high osmolarity and most of them are transported into the cytoplasm where they act as compatible solutes directly or after conversion (Csonka and Hanson 1991). They also frequently are accumulated in plants under osmotic or drought stress. Osmolyte transport systems have been linked to virulence in animal pathogens such as Escherichia coli, Staphylococcus aureus, or Listeria monocytogenes. Using large mutant pool screens, putP was identified as one of the major genes essential for in vivo survival of $S$. aureus (Bayer et al.

Corresponding author: K. Gloux; INRA, Unité d'Ecologie et de Physiologie du Système Digestif, Domaine de Vilvert, 78352 Jouy en Josas Cedex, France; Telephone: + 33 (0)1 346524 64; Fax: + 33 (0)1 346524 62; Email: gloux@diamant.jouy.inra.fr
1999). It was suggested that ProP, ProU, or both may contribute to the virulence of the uropathogenic E. coli strains (Chambers and Lever 1996). The contributions of the osmoprotectant uptake systems (ProU, ProP, and BetU) to urinary tract colonization vary between isolates (Culham et al. 2001). Furthermore, inactivation of the putP homologue in $S$. aureus or opuC in $L$. monocytogenes reduces the virulence of these bacteria (Sleator and Hill 2001; Sleator et al. 2001). Even if these uptake systems are not virulence determinants in the classical sense, they are considered to be contributory factors essential for several animal pathogens to mount a successful infection (Sleator and Hill 2001). However, their role has not yet been completely established and their contribution to plant-pathogen virulence has been little studied.

Erwinia chrysanthemi is a gram-negative enterobacterium inducing soft rot disease in a wide range of plants. Several studies have shown that osmotic stress induces virulence factors in this bacteria (Gouesbet et al. 1995; Hugouvieux-CottePattat et al. 1992; Mildenhall et al. 1988; Mildenhall and Prior 1983; Prior et al. 1994). Among the enzymes responsible for plant attack, the pectate lyases (Pel, EC 4.2.2.2) play a major role in the maceration of plant tissue (Collmer and Keen 1986). Pel activity is increased under high osmolarity conditions (Gouesbet et al. 1995; Hugouvieux-Cotte-Pattat et al. 1992) and this effect is reversed by the presence of osmoprotectants such as proline, glycine betaine, carnitine, pipecolic acid, or ectoine (Gouesbet et al. 1995; Prior et al. 1994). The transcription of pelE, encoding the major Pel, is induced by an osmotic stress and this effect is reversed by osmoprotectants supplementation (Gouesbet et al. 1995; Hugouvieux-CottePattat et al. 1992). At least two distinct osmoprotectant uptake systems are present in E. chrysanthemi 3937 (Gouesbet et al. 1996), but only osmoprotectants uptake system A (OusA), homologous to Escherichia coli ProP, has been characterized and described as the major pathway for the uptake of glycine betaine, proline, ectoine, and pipecolic acid (Gouesbet et al. 1996). The expression of ousA is strongly stimulated by osmotic upshift and a maximum induction level is maintained throughout growth and reversed by the addition of osmoprotectants (Gouesbet et al. 1996). Furthermore, ousA expressed in $E$. coli is controlled by the nucleoid-associated protein HNS (Gouesbet et al. 1996) whose homologue in Erwinia chrysanthemi and in many other pathogens plays a crucial role in the expression of virulence factors (Nasser et al. 2001).

A correlation between osmotic stress and pectate lyase activities has already been reported but the significance of this interaction in plant pathogenicity is still unknown. In the present work, the relationship between osmotic stress tolerance and 
the aggressiveness of several E. chrysanthemi strains were examined. Strains disrupted in ousA were used to investigate the involvement of this major osmoprotectant transport system in E. chrysanthemi virulence, maceration efficiency, and Pel production. To better understand the mechanism of ousA in virulence, the effect of ousA disruption on Pel production and pelE expression was studied in vitro. Finally, the respective roles of osmoprotection and the ousA gene in Pel production control were studied using different osmoprotectant molecules.

\section{RESULTS}

\section{Comparative virulence and osmotic tolerance of several $E$. chrysanthemi strains.}

In order to detect a hypothetical link between osmotolerance and virulence of E. chrysanthemi, eight strains were tested for their ability to cause tissue decay on intact potato tubers and for their tolerance to $\mathrm{NaCl}$ (growth under hyperosmotic conditions). The effect of $\mathrm{NaCl}$ supplementation on growth was strain dependent: increasing the $\mathrm{NaCl}$ concentration had no effect on growth of strain 3262 and ranged upward to $80 \%$ inhibition of growth for strain 3265 (Fig. 1). The most salt-sensitive strains caused the most severe infection, with $6 \mathrm{~g}$ of decayed tissue for strain 3265 compared with $1 \mathrm{~g}$ for strain 3262. Strain virulence was inversely related to salt tolerance (correlation $R^{2}=0.62$ ).

\section{The effect of oxygen status on virulence, maceration} efficiency, and Pel production in an ous $A$-deficient strain.

Strains disrupted in the ousA gene were used to investigate the potential involvement of OusA osmoprotectant transport system in the pathogenicity of E. chrysanthemi on two hosts differing in their tissue structure (Fig. 2). The ous $A^{-}$strain 4037 (ousA::uidA), previously well characterized (Gouesbet et al. 1996), showed a highly increased virulence on intact potato tubers compared with that of the wild-type strain 3937 (Fig.
3A). Similar results were obtained on chicory leaves. To better understand these results, we studied the maceration efficiencies of the strains on cut potato tubers. We assessed the role of the oxygen status in the ousA disruption effect by incubating under either ambient or anaerobic conditions. The maceration efficiency was not affected by the ousA gene disruption under ambient conditions (Fig. 3B). In contrast, under anaerobiosis, the ous $A^{-}$strain produced a larger amount of soft rot than under normal oxygen conditions and than the wild type (Fig. $3 B)$. In these anaerobically incubated cut tubers, the mutant grew to a higher population than did the wild type: $6.1 \pm 2.3 \times$ $10^{10}$ and $0.2 \pm 0.1 \times 10^{10} \mathrm{CFU} / \mathrm{g}$ of soft rot, respectively $(P=8$ $\left.\times 10^{-4}\right)$. Study of the Pel activities within these anaerobically macerated tissues by the cup-plate method (see Material and Methods) showed that the average diameter of the active zone was $1.4 \mathrm{~cm}$ with the mutant strain compared with $0.5 \mathrm{~cm}$ for the wild-type strain $(P<0.05)$.

The same virulence, maceration, and Pel activity experiments performed using 3941 (ousA:: $\Omega$ ), another differently constructed ousA mutant (Table 1; Fig. 2), confirmed these results (data not shown).

\section{Influence of ousA disruption and oxygen status on pectate lyase activity and pelE expression.}

Growth and virulence are interconnected in planta; therefore, in vitro experiments were performed in order to study the relationship between ousA expression, Pel production, and the oxygen status. In M63 medium, supplemented with an inducer of Pel activity and an electron acceptor (fumarate), the Pel activities of the ousA mutant strains (4037 and 3941) and the wild type were not significantly different under ambient oxygen conditions $\left(1.5 \pm 0.5 \mu \mathrm{mol} . \mathrm{min}^{-1} \mathrm{mg}^{-1}\right.$ dry weight [DW] $)$. In contrast, under micro-aerobic conditions, the Pel production of the mutants was significantly enhanced compared with that of the wild type: $6.37 \pm 1.20$ and $1.37 \pm 0.23 \mu \mathrm{mol} \mathrm{min}{ }^{-1} \mathrm{mg}^{-1}$ DW, respectively $(P=0.053)$. Fumarate supplementation as

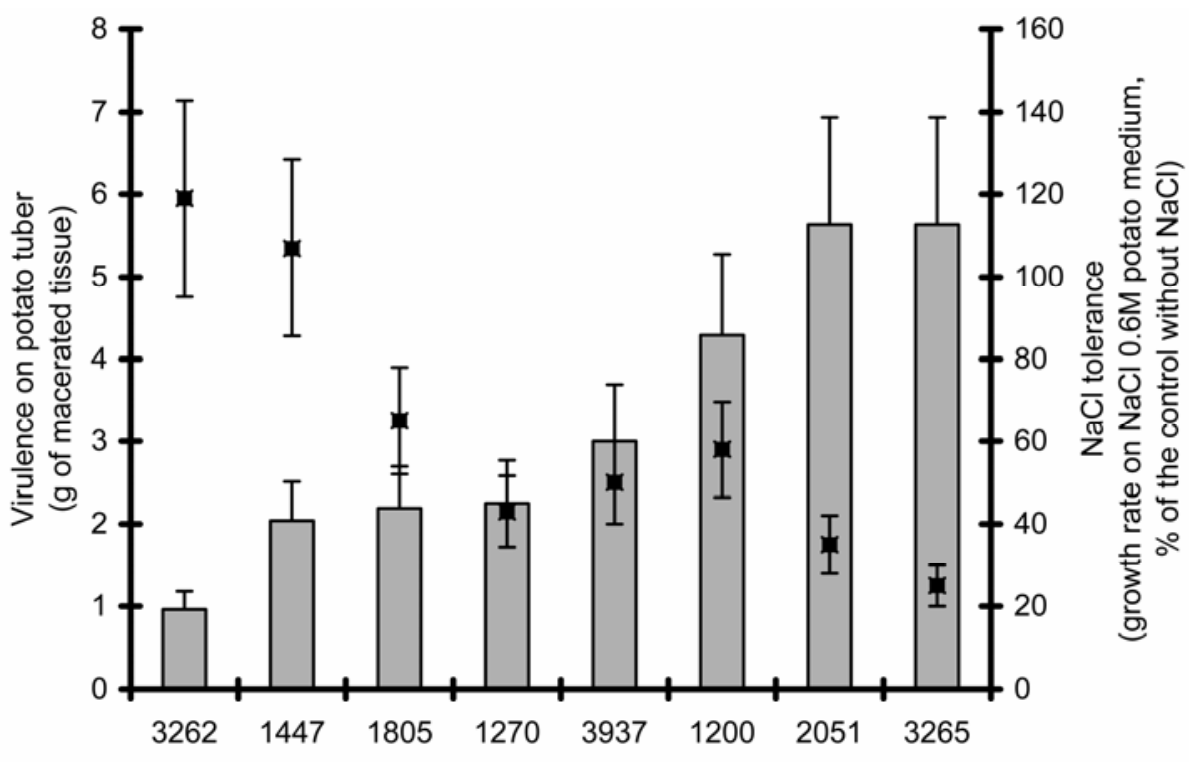

\section{E. chrysanthemi strains}

Fig. 1. Relationship between $\mathrm{NaCl}$ tolerance and virulence of Erwinia chrysanthemi strains on potato tuber. Squares and boxes represent $\mathrm{NaCl}$ tolerance and virulence results, respectively. $\mathrm{NaCl}$ tolerance was performed in culture on potato tuber pieces as unique substrate. The growth rates obtained in the presence of $0.6 \mathrm{M} \mathrm{NaCl}$ were expressed as a percentage of that observed without $\mathrm{NaCl}$ supplementation. The virulence test was performed on intact tuber and expressed as milligrams of macerated tissue. Potato tubers were inoculated by insertion in the parenchyma of sterile polypropylene pipette tips containing $20 \mu 1$ of the bacterial suspension $\left(2 \times 10^{8}\right.$ bacteria) and incubated under ambient oxygen status at $30^{\circ} \mathrm{C}$ in a dew chamber at $100 \%$ relative humidity. The weight of decayed tissue was measured after 3 days of incubation. Growth rate results are average and standard deviation of three independent experiments and virulence results were obtained from two independent experiments on at least six tubers with each strain. 
performed under micro-aerobic conditions did not significantly change Pel activities under ambient atmosphere.

In order to demonstrate a direct involvement of the ousA locus in Pel production, complementation tests were performed in vitro using the constructed plasmid pKG10 bearing the ous $A$ gene. Under micro-aerobiosis, the ous $A^{-}$mutant (4037) transformed with pKG10 demonstrated a lower Pel production than did the control strain (empty vector): $2.84 \pm 0.50 \mathrm{U}$ versus $6.80 \pm 1.25 \mathrm{U}$, respectively $(P=0.045)$. No significant effect of the ousA gene insertion in the plasmid was observed on the growth rate of the strain.

The effect of the ousA disruption on pelE gene control was studied using a GUS construction within pelE in the strain 3941 (ousA:: $\Omega$ ). The expression of pelE was significantly decreased by micro-aerobic conditions in the presence of ousA (Fig. 4). The disruption of ousA had no significant effect on pelE expression under ambient conditions but induced it sevenfold under micro-aerobiosis (Fig. 4). The Gus activity of the strain 4037 was measured under the same culture conditions: no significant effect of the oxygen status was observed on the ousA expression (GUS activity of $250 \pm 30 \mathrm{U}$, whatever the oxygen status).

\section{ous $A$ disruption and osmoprotectants effects on Pel production.}

The effects of osmoprotectants on the behavior of the wildtype and mutant strain were examined, and cells were grown on M63 medium supplemented with glycerol (carbon source), fumarate (electron acceptor), and galacturonate (Pel inducer), generating an osmotic pressure of $800 \mathrm{mOsm}$. The addition of $1 \mathrm{mM}$ of any one of the osmoprotectants, proline, glycine betaine, or pipecolic acid, had no significant effect on the growth rate of the wild type under micro-aerobic conditions (Table 2). In contrast, the growth rate of the mutant was elevated by the addition of osmoprotectants under micro-aerobic conditions, glycine betaine being the most effective compound (Table 2). Osmoprotectants and ousA disruption effects on Pel production were studied in more detail under micro-aerobiosis. Pel production of the wild-type strain was severely decreased by proline, glycine betaine, and pipecolic acid in this assay, the latter being the most effective (Table 2). An effect of the osmoprotectants on Pel production was also observed in absence of an intact ousA gene. The efficiency of glycine betaine in reducing Pel production was not significantly modified by ousA disruption (Table 2). The effects of proline and pipecolic acid was only weakly reduced (32 and $18 \%$, respectively).

The osmotic pressure developed by the fumarate supplementation decreased the growth rate of the mutant (less $\mathrm{NaCl}$ tolerant than the wild type), allowing an elevation of the growth rate by the three osmoprotectants (Table 2). The efficacies of the three compounds to repress Pel production were not correlated to their effects on growth.

\section{DISCUSSION}

The observation that the less $\mathrm{NaCl}$-tolerant $E$. chrysanthemi strains are the more virulent, based on the potato assay, is consistent with a previous report demonstrating common regula-

Plasmid Vector

pSU21
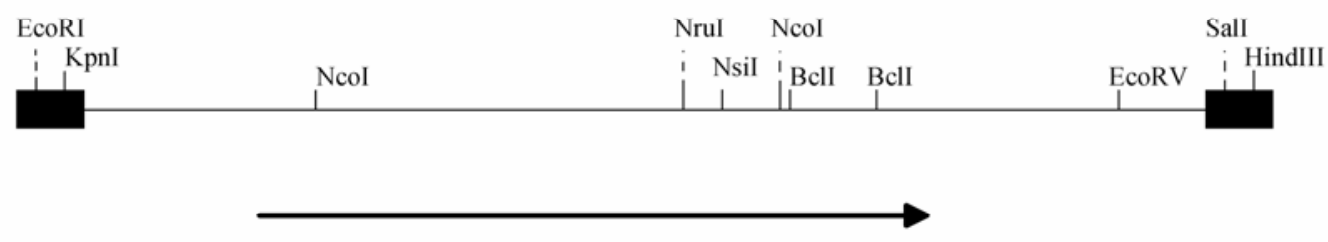

ousA
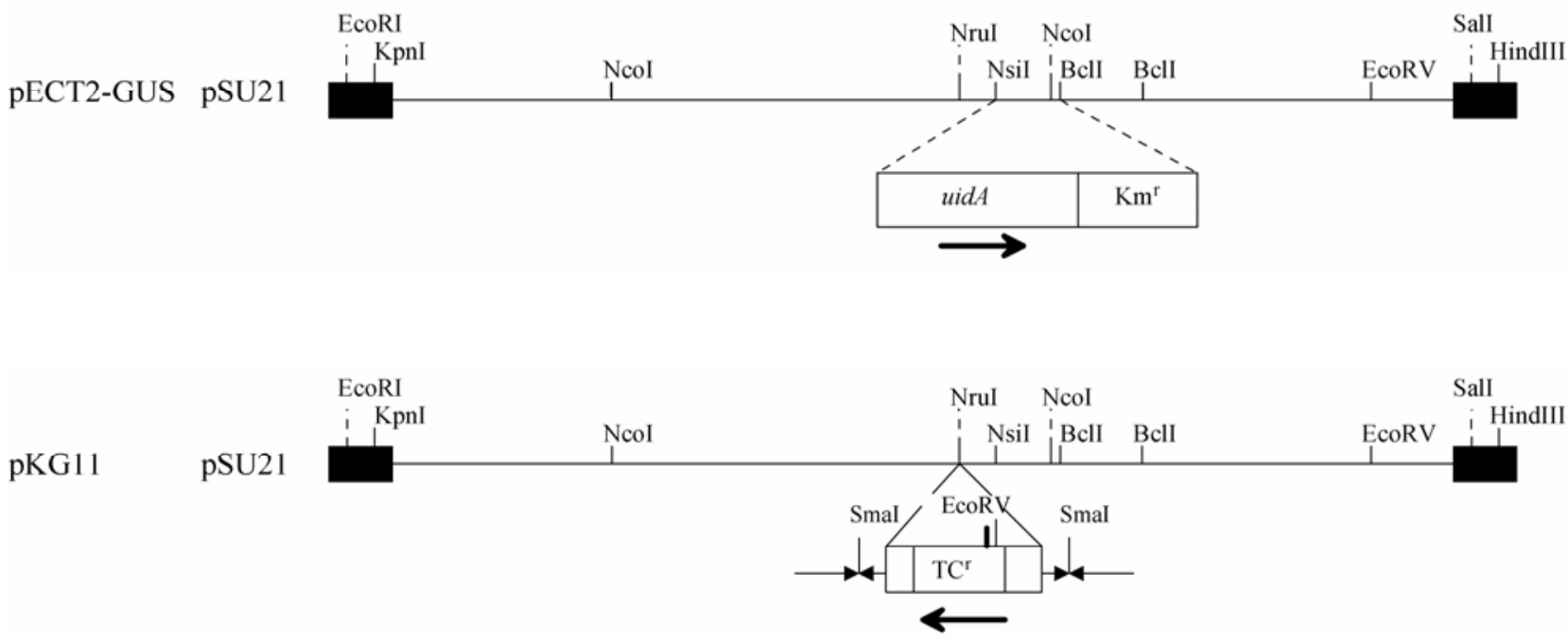

Fig. 2. Construction of the ous $A^{-}$strains 4037 (ousA::uidA) and 3941 (ousA:: $\Omega$ ). pECT2-1 and pECT2-GUS constructions were those obtained by Gouesbet and associates (1996). Erwinia chrysanthemi DNA is represented by the thin line; pSU21 polylinkers are shown as solid boxes. The dashed arrows show the orientation of uidA transcription and antibiotic resistance genes. The small arrows (directed outwards from the interposon) indicate the transcriptional termination signals of bacteriophage T4D gene 32, and the filled large triangles represent the translation stop box whose sequence was given by Prentki and Krisch (1984). Km = kanamycin and TC = tetracycline. 
tory mechanisms for virulence factors and osmotic environmental stress in this bacterium (Nasser et al. 2001). A similar correlation was previously observed between the osmotic tolerance of several pseudomonads and their ability to colonize potato root systems (Loper et al. 1985). However, further investigation failed to demonstrate a relationship between an osmotolerance mechanism and plant colonization (Howie et al. 1990). Our results demonstrate that E. chrysanthemi aggressiveness is enhanced in an ousA mutant. The similar behaviors of the two ous $A^{-}$strains indicates that the relationship of ousA

3937

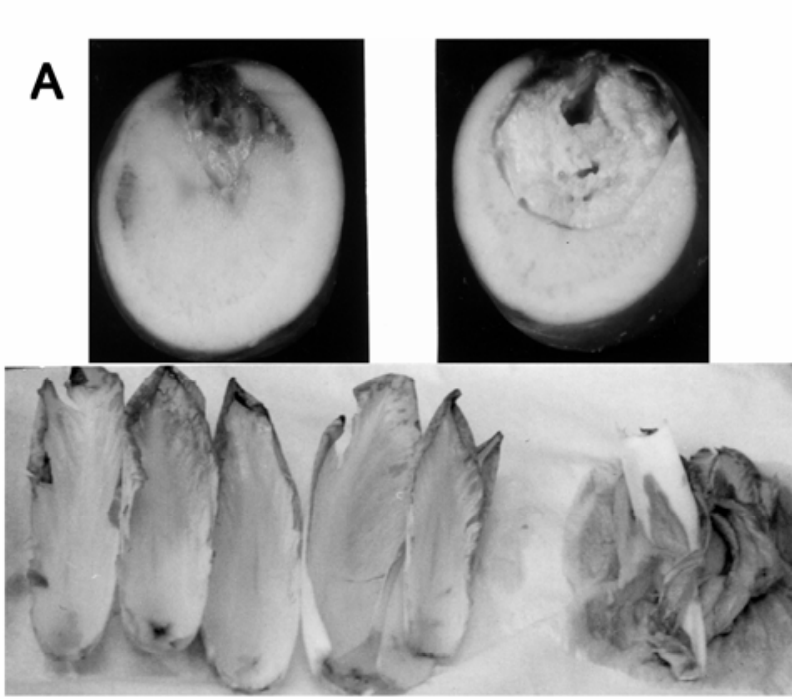

B

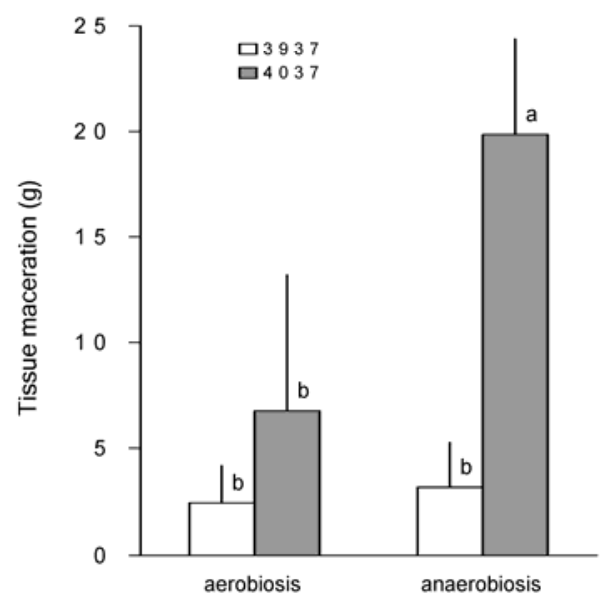

Fig. 3. In planta behavior of the Erwinia chrysanthemi ousA mutant. A, Virulence on intact potato tuber. Potato tubers were inoculated by insertion in the parenchyma of sterile polypropylene pipette tips containing $20 \mu \mathrm{l}$ of the bacterial suspension $\left(2 \times 10^{8}\right.$ bacteria) and incubated under ambient oxygen status at $30^{\circ} \mathrm{C}$ in a dew chamber at $100 \%$ relative humidity. B, Maceration efficiency under aerobiosis and anaerobiosis. One-half of a tuber cylinder was inoculated with the wild-type strain 3937, the other half with the ousA mutant strain 4037. Aerobically incubated organs were exposed to ambient oxygen. Anaerobic conditions were obtained by incubation in anaerobic jars. For virulence or maceration tests, at least six organs or half-cut tubers were inoculated with each strain in each experiment. Intact and half-cut potato tubers were observed after 3 days of incubation. Results are averages and standard deviations of at least 12 inoculation sites. Statistical analysis was performed with STAT ITCF and homogeneous groups $(a, b)$ were obtained by the Neuman-Keuls test. Similar results were obtained with the strain 3941 (ousA $:: \Omega$ ).
Table 1. Influence of osmoprotectants on pectate lyase activity of the ous $A^{-}$mutant (4037) compared with the wild strain (3937) ${ }^{\mathrm{a}}$

\begin{tabular}{lccc}
\hline $\begin{array}{l}\text { Strain, } \\
\text { osmoprotectant }\end{array}$ & $\begin{array}{c}\text { Doubling time } \\
\text { (h) }\end{array}$ & $\begin{array}{c}\text { Pel production } \\
(\mathbf{U})\end{array}$ & $\begin{array}{c}\text { Repression of Pel } \\
\text { production (\%) }\end{array}$ \\
\hline 3937 & & & \\
$\quad$ None & 6.7 & 1.37 & $\ldots$ \\
Proline & 6.0 & 0.30 & 78 \\
Glycine betaine & 6.4 & 0.27 & 80 \\
Pipecolic acid & 6.7 & 0.14 & 90 \\
4037 (ous $A^{-}$) & & & $\ldots$ \\
None & 12.0 & 6.37 & 46 \\
Proline & 9.8 & 3.44 & 83 \\
Glycine betaine & 8.6 & 1.08 & 72 \\
Pipecolic acid & 10.1 & 1.78 & \\
\hline
\end{tabular}

${ }^{a}$ Cells were grown under micro-aerobiosis conditions in M63 medium containing glycerol at $4 \mathrm{~g}$ per liter, fumarate at $25 \mathrm{~g}$ per liter, and galacturonate at $2 \mathrm{~g}$ per liter. Osmoprotectants were added at a concentration of $1 \mathrm{mM}$ in the culture medium. Kinetics were performed in order to determine the maximum Pel activity. Specific activity is expressed as umoles of unsaturated products liberated per minute per milligram of bacterial dry weight. Results were means of three independent experiments and standard deviation was less than $10 \%$ for the doubling time and $20 \%$ for Pel production.

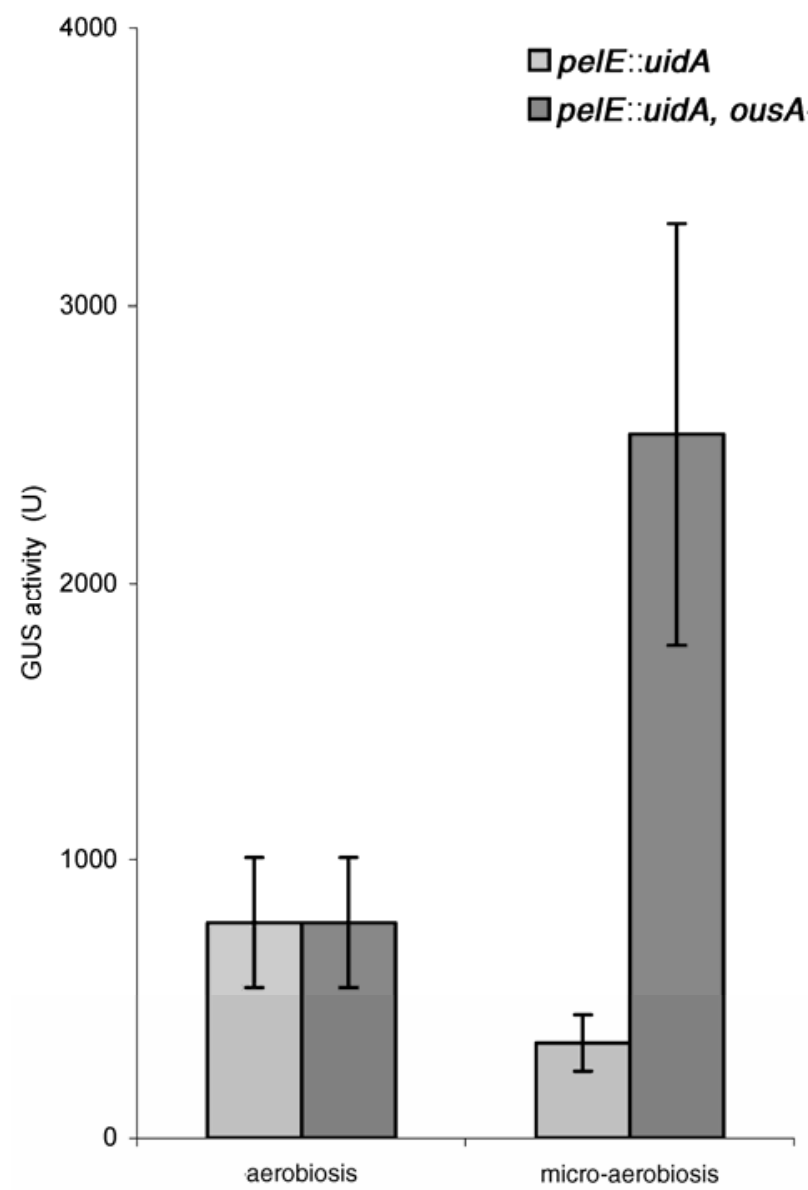

Fig. 4. Influence of ousA disruption on pelE expression in vitro under ambient oxygen status and micro-aerobiosis. Strains were grown in M63gly medium supplemented with glycerol at $4 \mathrm{~g}$ per liter as carbon source, galacturonate at $2 \mathrm{~g}$ per liter to induce pectate lyases production, and the appropriate antibiotic. Fumarate at $25 \mathrm{~g}$ per liter was added for anaerobic conditions but also under ambient oxygen status to maintain the same osmotic pressure. Kinetics were performed in each case, in order to determine the maximum expression. GUS activity was expressed as nmole of product liberated per minute per milligram of bacterial dry weight. The results reported are the average of at least three independent experiments. 
with virulence repression mechanisms is not a peculiarity of one strain. The inhibitory effect of ousA is consistent with the capacity of osmoprotectants to suppress Pel production (Gouesbet et al. 1995). Considering that osmoprotectant uptake systems contribute to increased osmotolerance, the involvement of ousA in a negative control of aggressiveness is also concordant with the negative relationship between aggressiveness and osmotic stress tolerance in the various $E$. chrysanthemi strains tested.

The inhibitory effect of ousA is surprising in regard to previous studies performed with animal pathogens. Indeed, osmoprotectant transport disruptions decrease the virulence of $E s$ cherichia coli, S. aureus, and L. monocytogenes (Bayer et al. 1999; Chambers and Lever 1996; Culham et al. 2001; Sleator and Hill 2001; Sleator et al. 2001). Generally, osmoprotectant uptake systems are considered to be essential for the pathogen to mount a successful infection via an increased resistance to environmental stresses. In contrast, our results demonstrate that ousA plays an inhibitory role on virulence. However, other pathogen-host systems may be studied to determine if this negative effect represents a general difference between regulation of pathogenicity in plant and animal hosts.

The ousA disruption effects on the maceration efficiency, Pel production, and population level per gram of macerated tissue are enhanced when the tubers are incubated under anaerobiosis. These results suggest that the ousA gene plays a role in a process negatively controlling bacterial proliferation within the tissue under anaerobiosis.

In vitro experiments provide more information on the mechanisms involved. Because ousA mutation in strain 4037 was created by the insertion of an uidA-KanR cassette that could have had a polar effect, its influence could have resulted from the lack of transcription of a gene distal from ousA. The same behavior of the differently constructed strain 3941 in regard to its virulence, maceration efficiency, and Pel activity supports a direct involvement of ousA. Finally, the complementation experiments performed in vitro confirmed a direct relationship between ousA and Pel production control, specifically under micro-aerobiosis. Therefore, our results suggest that the ousA gene product may be implicated in aggressiveness inhibition more specifically in the absence of oxygen. The micro-aerobiosis-dependent induction of pelE expression observed in the $o u s A^{-}$strain argues for a control at the transcriptional level of the gene encoding the major Pel produced in planta. This result argues definitively for a direct involvement of ousA in Pel production. In contrast to previous results (Hugouvieux-CottePattat et al. 1992), pelE was not induced under micro-aerobiosis. The difference may be due to the fumarate supplementation under both oxygen conditions during our experiments. Indeed, the addition of fumarate develops an osmotic pressure similar to an $\mathrm{NaCl}$ supplementation, allowing maximal induction of pelE (Gouesbet et al. 1995).

Our results in planta and in vitro demonstrate the involvement of ousA in the control of virulence and maceration under anaerobic conditions. A role of the tissue oxygen status in the maceration by pectic enzymes has been described for Erwinia spp. (Maher and Kelman 1983). The oxygen content is significantly higher in healthy tissue than in soft rot (Smid et al. 1993). Our data suggest that the higher oxygen content in the healthy tissue may reverse the ousA effect on Pel production and maceration. According to this assumption, the ousA gene would play a crucial role in disease progression within the potato tuber, specifically for the bacterial subpopulation localized at the boundary of the infection. Furthermore, micro-aerobiosis had no effect on ousA expression and on the maceration efficiency of the wild-type strain. Therefore, the oxygen status effect was not due to an ousA expression control or the modification of the transporter efficiency.

In vitro experiments performed in the presence of the osmoprotectants (glycine betaine, proline, and pipecolic acid), showed that the effect of proline on Pel production is the most affected by ousA disruption. The experiments also showed that ous $A$ has an effect on Pel production in the absence of added osmoprotectant, demonstrating that its role is not exclusively linked to the uptake of these compounds.

The experiments also involved a comparative study of the osmoprotectant capacities to restore growth and to inhibit Pel production. The respective osmoprotectant efficiencies to restore the growth of the mutant strain 4037 were concordant with previous results (Gouesbet et al. 1995). The persistence of osmoprotectant effects on Pel production in the mutant is not surprising and may be the result of an uptake compensation via other uptake systems present in E. chrysanthemi (Gouesbet et al. 1996). Furthermore, the osmoprotectants efficacies to restore growth (Table 2) (Gouesbet et al. 1996) were not correlated to the effects on Pel production, suggesting an involve-

Table 2. Bacterial strains and plasmids

\begin{tabular}{|c|c|c|}
\hline Strain, phage, or plasmid & Genotype or description $^{\mathrm{a}}$ & Reference or source \\
\hline \multicolumn{3}{|l|}{ Bacterial strain } \\
\hline \multicolumn{3}{|l|}{ Erwinia chrysanthemi } \\
\hline 3937 & Wild type & Kotoujansky et al., 1982 \\
\hline 4037 & ousA::uidA, $\mathrm{Km}^{\mathrm{r}}$ & Gouesbet et al., 1996 \\
\hline 3941 & ous $A:: \Omega$, Tet $^{\mathrm{r}}$ & This study \\
\hline A1828 & pelE::uidA, $\mathrm{Km}^{\mathrm{r}}$ & Hugouvieux-Cotte-Pattat et al., 1992 \\
\hline A2828 & pelE::uidA $\mathrm{Km}^{\mathrm{r}}$, ousA $:: \Omega \mathrm{Tet}^{\mathrm{r}}$ & This study \\
\hline \multicolumn{3}{|l|}{ Escherichia coli } \\
\hline GM46 & $\mathrm{dam}^{-}$ & Brooks et al., 1983 \\
\hline MC4100 & $F^{-}$araD1394(argF-lac)U169 rpsL150 relA1 deoC1 ptsF25 flbB5301 rbsR & Stratagene \\
\hline MKH13 & MC4100A(putPA) $101 \Delta($ proP $) 2 \Delta($ proU $) 608$ & E. Bremer \\
\hline \multicolumn{3}{|c|}{ F } \\
\hline phi-EC2 & E. chrysanthemi generalized transduction phage & Resibois et al., 1984 \\
\hline \multicolumn{3}{|c|}{. } \\
\hline pUIDK1 & uida cassette, $\mathrm{Km}^{\mathrm{r}}, \mathrm{Ap}^{\mathrm{r}}$ & Bardonnet and Blanco, 1992 \\
\hline pSU21 & $\mathrm{Cm}^{\mathrm{r}}$ & Martinez et al., 1988 \\
\hline pHP45 $\Omega$ & $\Omega$ fragment, Tet ${ }^{r}$ & Prentki and Krisch 1984 \\
\hline pKG11 & $\mathrm{pHP} 45 \Omega$, Tet $^{\mathrm{r}}$, ousA & this study \\
\hline pECT2-1 & pSU21, $\mathrm{Cm}^{\mathrm{r}}$ ous A & Gouesbet et al., 1996 \\
\hline pECT2-GUS & pSU21, $\mathrm{Cm}^{\mathrm{r}}$ ousA::uidA & Gouesbet et al., 1996 \\
\hline pBBR1MCS-5 & Gent $^{\mathrm{r}}$ & Kovach et al., 1995 \\
\hline pKG10 & pBBR1MCS-5 derivative bearing ousA, Gent ${ }^{\mathrm{r}}$ & This study \\
\hline
\end{tabular}

\footnotetext{
${ }^{\mathrm{a}} \mathrm{Km}=$ kanamycin, $\mathrm{Tet}=$ tetracyclin, $\mathrm{Ap}=$ ampicillin, $\mathrm{Cm}=$ chloramphenicol, Gent = gentamycin.
} 
ment in the Pel regulatory network not directly linked to the ability to restore isoosmotic conditions in cell.

The roles of ousA and osmoprotectants in virulence are difficult to analyze because available osmoprotectants, osmotic pressure, and bacterial metabolism may depend upon the maceration time and the distance from the boundary of the infection. However, the osmotic strength of the macerated tissue (estimated at approximately $350 \mathrm{mOsm}$ [personal results]) is not sufficient to induce a high expression of ousA as observed by Gouesbet and associates (1996). Osmoprotectant levels in plants that naturally accumulate them are typically in the range of 5 to $50 \mu \mathrm{mol} \mathrm{g}{ }^{-1}$ fresh weight ( 6 to $60 \mathrm{mM}$ on a plant water basis) (Rontein et al. 2002), allowing an effect on Pel production and virulence. Proline, naturally occurring in potato tubers (Ambard-Bretteville et al. 2003; Jaarma 1966), may be liberated during the infection, taken up via OusA, and repress Pel production and potato tuber infection. It also is noteworthy that pipecolic acid is also present in the potato tuber macerated tissue (data not shown). Other plant compounds that may be taken up via OusA could be more efficient or show synergistic effects on Pel production. Unknown plant environmental factors also may regulate ousA expression. Resistance of potato to E. chrysanthemi is evident only under anaerobiosis (Allefs et al. 1995); therefore, race-cultivar susceptibilities may be related to the osmoprotectant content. Because ousA and pel genes are controlled in an opposite manner by the nucleoid-associated protein H-NS (Nasser and Reverchon 2002), further investigations will be necessary to determine the specific role of ousA in the regulatory network of Pel production. The involvement of regulation by noncoding RNAs in the coordinated control of OusA and Pel activities by anaerobiosis also may be suggested in regard to the role of such RNA in Escherichia coli adaptation processes and especially H-NS translation (Repoila et al. 2003).

\section{MATERIALS AND METHODS}

\section{Bacterial strains and culture conditions.}

The bacterial strains and plasmids used in this study are listed in Table 1. Other Erwinia chrysanthemi strains were purchased from CFBP (Collection Française des bactéries phytopathogènes, INRA, Angers, France). Cells were grown at $30^{\circ} \mathrm{C}$ in either Luria-Bertani (LB) or minimal M63 media (Miller 1992) supplemented with glycerol at $4 \mathrm{~g} \mathrm{liter}^{-1}$ (SigmaAldrich, St. Louis) as sole carbon source (M63gly). When required, the media were solidified with Difco agar at $15 \mathrm{~g} \mathrm{liter}^{-1}$ (Difco Laboratories, Detroit).

Osmotic tolerance screening was performed under ambient atmosphere. Elevated osmotic strength was obtained by $\mathrm{NaCl}$ supplementation and osmotic pressure was measured using a microosmometer (H. Roebling; Bioblock Scientific, Strasbourg, France). Growth rates were measured in cultures on potato tuber pieces, as unique substrate enveloped in a dialysis bag. Growth was monitored at an optical density at $600 \mathrm{~nm}\left(\mathrm{OD}_{600}\right)$. Three independent experiments were performed for each strain.

In vitro Pel activity experiments were performed in M63 medium supplemented with $0.2 \%$ galacturonate to induce Pel activity. For micro-aerobic conditions, fumarate at $25 \mathrm{~g} \mathrm{liter}^{-1}$ was added (Hugouvieux-Cotte-Pattat et al. 1992) and bacteria were grown in syringes. At least three independent experiments were performed for each strain under each culture condition.

In pelE and ousA expression experiments, fumarate supplementation was performed under both oxygen status conditions in order to maintain the same osmotic pressure (an average of $800 \mathrm{mOsm}$ ). The osmoprotectant compounds glycine betaine, proline, and pipecolic acid (Sigma-Aldrich) were supplied at a final concentration of $1 \mathrm{mM}$, allowing the maximum osmoprotecting effect on growth (Gouesbet et al. 1995). Bacterial growth was monitored at $\mathrm{OD}_{600}$. When required, kanamycin $(\mathrm{Km})$ and gentamycin (Gent) (Sigma-Aldrich) were added at $10 \mu \mathrm{g} \mathrm{ml}^{-1}$. At least three independent experiments were performed for each strain under each culture condition.

\section{Strain constructions.}

E. chrysanthemi was transformed by electroporation (Ausubel et al. 1994). DNA manipulations were carried out using standard methods (Sambrook et al. 1989). The mutants used in this study are isogenic derivatives of the wild-type 3937 strain, bearing a disrupted ousA gene, 4037 (ousA::uidA), and 3941 (ousA:: $\Omega$ ). Strain 4037 was previously constructed using a UIDK1 cassette (Gouesbet et al. 1996) (Fig. 2). To generate 3941 (ousA:: $\Omega$ ), Escherichia coli strain GM46 was transformed by the plasmid pECT2-1 bearing the ousA gene. The SmaI fragment of pHP45 (Prentki and Krisch 1984) was introduced in pECT2-1 at the Nru1 sites generating pKG11 (Fig. 2). EcoRV digestion of pKG11 implemented the localization and the insert orientation. Finally, the wild-type strain 3937 was transformed by pKG11 in order to generate the chromosomic insertion ous $A:: \Omega$, this plasmid being unable to replicate in Erwinia chrysanthemi. Plasmids were constructed in order to study the ousA::uidA complementation. The pUC18 derivative pECT2-1(ous $A^{+}$) (Gouesbet et al. 1996) was unstable in E. chrysanthemi, whereas pBBR1MCS-5 (Kovach et al. 1995) has been shown to maintain. The EcoRIHindIII fragment of pECT2-1 was transferred into pBBR1MCS5 generating pKG10 (Table 1). The recombinant plasmid was introduced by electroporation into Escherichia coli MKH13 (deleted for prop, proU, and putPA) and the efficiency of the ousA gene, controlled through the restoration of proline osmoprotectant effect in the presence of $0.7 \mathrm{M} \mathrm{NaCl}$, implemented correct DNA insertion. Finally, we introduced the plasmid pKG10 in strain 4037.

To construct pelE::uidA, ousA:: $\Omega$ strain, a pSU21 bearing ousA (pECT2-1) (Gouesbet et al. 1996) was introduced in an Escherichia coli, dam (GHM46). An NruI (ous $\left.{ }^{+}\right)$fragment was introduced in $\mathrm{pHP} 45 \Omega$, cleaved by SmaI, generating pKG11 (Table 1). The resulting plasmid was introduced in 3937, generating a chromosomal insertion ous $A: \Omega \Omega$. The resultant strain, bearing a pelE::uidA fusion, was transducted by a phi-EC $\mathrm{C}_{2}$ stock made on 3941 (ousA:: $\Omega$ ), generating the strain A2828.

\section{Potato inoculation technique, maceration assessment, and population level measurement.}

Virulence tests were performed on intact potato tuber (cv. Bintje). Plant organs were selected for uniform size and absence of injury or disease. Intact potato tubers were surface sterilized by immersion in $0.5 \%$ sodium hypochlorite for $40 \mathrm{~min}$, rinsed with sterile deionized water, and air dried under a laminar flow hood. Bacteria were grown in M63Gly medium and calibrated at $2 \times 10^{8}$ bacteria per $20 \mu \mathrm{l}$ before inoculation. For strains bearing pBBR1MCS-5 or PKG10, gentamycine at $10 \mu$ liter $^{-1}$ was added to the culture medium. Potato tubers were inoculated by insertion in the parenchyma of sterile polypropylene pipette tips containing $20 \mu \mathrm{l}$ of the bacteria suspension and incubated at $30^{\circ} \mathrm{C}$ in a dew chamber at $100 \%$ relative humidity. Virulence results are presented on photographs or expressed as gram of macerated tissue.

The maceration efficiency was compared using two halfcuts of the same potato tubers. One half was inoculated with the wild-type strain and the other half with the mutant. The weight of decayed tissue was measured and considered as characteristic of maceration severity.

For virulence or maceration tests, at least six organs or six half-cut tubers were inoculated with each strain in at least 
three experiments. Aerobically incubated organs were exposed to ambient atmosphere. Anaerobic conditions were obtained by incubation in anaerobic jars and symptoms were observed 3 days after inoculation. Absence of contaminants was controlled on LB agar plates using the appropriate antibiotics. The number of bacteria present in the soft rot was determined from at least six half-cut tubers after successive dilutions on LB agar plates in the presence of the appropriate antibiotics.

\section{Enzyme activities measurement.}

The uidA-Km cassette present in 4037 (ousA-), A1828 (pelE-), and A2828 (pelE, ousA) allowed the measurement of the expression of the genes of interest. $\beta$-Glucuronidase activities were measured on toluen-permeabilized cells with p-nitrophenyl-glucuronide ( $\mathrm{pNpG)}$ as substrate (Bardonnet and Blanco 1992). Specific activity was expressed as nmole of $\mathrm{p}$ nitrophenyl liberated per minute per milligram of bacterial dry weight. The results reported are the average of at least three independent experiments.

Pectate lyase activities in the soft rot were determined by the semiquantitative cup-plate method of Dingle and associates (1953). The compositions of agarose media were as followed: $1 \%$ polygalacturonic acid (PGA), $1 \%$ yeast extract, $0.38 \mu \mathrm{M}$ $\mathrm{CaCl}_{2}$, and $100 \mathrm{mM}$ Tris- $\mathrm{HCl}, \mathrm{pH} 8.5$. In addition, the medium was supplemented with $0.8 \%$ agarose and $0.2 \%$ sodium azide. A 20- $\mu$ l aliquot of successive dilutions of $1,0.1$, and 0.01 of the potato-macerated tissues were dropped in each plate. Activities were expressed as millimeters of the active zone. The results are the average of three independent experiments on at least six half-cut potato tubers and the standard deviation (SD) was less than $15 \%$ in each case.

Quantitative assays in culture were performed on toluenized cell extracts in $10 \mathrm{mM}$ Tris- $\mathrm{HCl}(\mathrm{pH}$ 8.6) by monitoring at $\mathrm{OD}_{235}$ the degradation of polygalacturonate (HugouvieuxCotte-Pattat et al. 1992). Kinetics of growth and activities were performed in each case to determine the maximum activity. Specific activities were expressed as $\mu$ moles of unsaturated uronic acid released per minute per milligram of bacterial dry weight. Results reported are means of at least three independent experiments, and the SD was less than $10 \%$ in each case. The term Pel production was used throughout this article to avoid confusion with enzymatic activity generally referring to the enzyme itself.

\section{Statistical analysis.}

StatView 4.0 (Abacus Concept Inc., Berkeley, CA, U.S.A.) was used for the statistical analysis. Homogeneous groups $(a, b)$ were obtained by the Neuman-Keuls test. Others statistical analyses were performed with the Student test.

\section{LITERATURE CITED}

Allefs, J. J. H. M., Van Dooijeweert, W., De Jong, E. R., Prummel, W., and Hoogendoorn, J. 1995. Factors affecting potato soft rot resistance to pectolytic Erwinia species in a tuber-slice assay. J. Phytopathol. 143:705-711.

Ambard-Bretteville, F., Sorin, C., Rebeille, F., Hourton-Cabassa, C., and Colas des Francs, C. 2003. Small repression of formate dehydrogenase in Solanum tuberosum increases steady-state levels of formate and accelerates the accumulation of proline in response to osmotic stress. Plant. Mol. Biol. 52:1153-1168.

Ausubel, F. M., Brent, R., Kingston, R. E., Moore, D. D., Seidman, J. G., Smith, J. A., and Struhl, K. 1994. Currents Protocols in Molecular Biology. John Wiley and Sons, Inc., New York.

Bardonnet, N., and Blanco, C. 1992. uidA-antibiotic-resistance cassettes for insertion mutagenesis, gene fusions and genetic constructions. FEMS (Fed. Eur. Microbiol. Soc.) Microbiol. Lett. 72:243-247.

Bayer, A. S., Coulter, S. N., Stover, C. K., and Schwan, W. R. 1999. Impact of the high-affinity proline permease gene (putP) on the virulence of Staphylococcus aureus in experimental endocarditis. Infect. Immun. 67:740-744.

Brooks, J. E., Blumenthal, R. M., and Gingeras, T. R. 1983. The isolation and characterization of the Escherichia coli DNA adenine methylase (dam) gene. Nucleic Acids Res. 11:837-851.

Chambers, S. T., and Lever, M. 1996. Betaines and urinary tract infections. Nephron 74:1-10.

Collmer, A., and Keen, N. T. 1986. The role of pectic enzymes in plant pathogenesis. Annu. Rev. Phytopathol. 24:383-409.

Csonka, L. N., and Hanson, A. D. 1991. Prokaryotic osmoregulation: Genetics and physiology. Annu. Rev. Microbiol. 45:569-606.

Culham, D. E., Lu, A., Jishage, M., Krogfelt, K. A., Ishihama, A., and Wood, J. M. 2001. The osmotic stress response and virulence in pyelonephritis isolates of Escherichia coli: Contributions of RpoS, ProP, ProU and other systems. Microbiology 147:1657-1670.

Dingle, J., Reid, W. W., and Solomons, G. L. 1953. The enzymatic degradation of pectin and other polysaccharides. II-Application of the 'cupplate' assay to the estimation of enzymes. J. Sci. Food Agric. 4:149-155.

Gouesbet, G., Jebbar, M., Bonnassie, S., Hugouvieux-Cotte-Pattat, N., Himdikabbab, S., and Blanco, C. 1995. Erwinia chrysanthemi at high osmolarity-Influence of osmoprotectants on growth and pectate lyase production. Microbiology 141:1407-1412.

Gouesbet, G., Trautwetter, A., Bonnassie, S., Wu, L. F., and Blanco, C. 1996. Characterization of the Erwinia chrysanthemi osmoprotectant transporter gene ousA. J. Bacteriol. 178:447-455.

Howie, W. J., Gutterson, N. I., and T. V. S. 1990. Osmotolerance-minus mutants of Pseudomonas putida strain MK280 are not impaired in cotton spermosphere and rhizosphere colonization. Soil Biol. Biochem. 22:839-844.

Hugouvieux-Cotte-Pattat, N., Dominguez, H., and Robert-Baudouy, J. 1992. Environmental conditions affect transcription of the pectinase genes of Erwinia chrysanthemi 3937. J. Bacteriol. 174:7807-7818.

Jaarma, M. 1966. The influence of ionizing radiation on the proline content in potato tubers. Acta Chem. Scand. 20:323-327.

Kotoujansky, A., Lemattre, M., and Boistard, P. 1982. Utilization of a thermosensitive episome bearing transposon TN10 to isolate Hfr donor strains of Erwinia carotovora subsp. chrysanthemi. J. Bacteriol. 150:122-131

Kovach, M. E., Elzer, P. H., Hill, D. S., Robertson, G. T., Farris, M. A., Roop, R. M., 2nd, and Peterson, K. M. 1995. Four new derivatives of the broad-host-range cloning vector pBBR1MCS, carrying different antibiotic-resistance cassettes. Gene 166:175-176.

Loper, J. E., Haack., C., and Schroth, M. N. 1985. Population dynamics of soil pseudomonads in the rhizophere of potato (Solanum tuberosum L.) Appl. Environ. Microbiol. 49:416-422.

Maher, E. A., and Kelman, A. 1983. Oxygen status of potato tuber tissue in relation to maceration by pectic enzymes of Erwinia carotovora. Phytopathology 75:536-539.

Martinez, E., Bartolome, B., and de la Cruz, F. 1988. pACYC184derived cloning vectors containing the multiple cloning site and lac $Z$ alpha reporter gene of pUC8/9 and pUC18/19 plasmids. Gene 68:159162.

Mildenhall, J. P., Lindner, W. A., Prior, B. A., and Tutt, K. 1988. Elevation and release of cell-associated pectate lyase in Erwinia chrysanthemi by lithium and sodium chloride. Phytopathology 78:213-217.

Mildenhall, J. P., and Prior, B. A. 1983. Water relations of Erwinia chrysanthemi: Growth and extracellular pectic acid lyase production. J. Gen. Microbiol. 127:27-34.

Miller, J. H. 1992. A Short Course in Bacterial Genetics. Cold Spring Harbor Laboratory, Cold Spring Harbor, NY, U.S.A.

Nasser, W., Faelen, M., Hugouvieux-Cotte-Pattat, N., and Reverchon, S. 2001. Role of the nucleoid-associated protein H-NS in the synthesis of virulence factors in the phytopathogenic bacterium Erwinia chrysanthemi. Mol. Plant-Microbe Interact. 14:10-20.

Nasser, W., and Reverchon, S. 2002. H-NS-dependent activation of pectate lyases synthesis in the phytopathogenic bacterium Erwinia chrysanthemi is mediated by the PecT repressor. Mol. Microbiol. 43:733-748.

Prentki, P., and Krisch, H. M. 1984. In vitro insertional mutagenesis with a selectable DNA fragment. Gene 29:303-313.

Prior, B. A., Hewitt, E. V., Brandt, E. V., Clarke, A., and Mildenhall, J. P. 1994. Growth, pectate lyase production and solute accumulation by $E r-$ winia chrysanthemi under osmotic stress: Effect of osmoprotectants. J. Bacteriol. 77:433-439.

Repoila, F., Majdalani, N., and Gottesman, S. 2003. Small non-coding RNAs, co-ordinators of adaptation processes in Escherichia coli: The RpoS paradigm. Mol. Microbiol. 48:855-861.

Resibois, A., Colet, M., Faelen, M., Schoonejans, E., and Toussaint, A. 1984. Phi-EC2, a new generalized transducing phage of Erwinia chrysanthemi. Virology 137:102-112.

Rhodes, D., and Hanson, A. D. 1993. Quaternary ammonium and tertiary 
sulfonium compounds in higher plants. Annu. Rev. Plant Physiol. Plant Mol. Biol. 44:357-384.

Rontein, D., Basset, G., and Hanson, A., D. 2002. Metabolic engineering of osmoprotectant accumulation in plants. Metab. Eng. 4:49-56.

Sambrook, J., Fritsch, E. F., and Maniatis, T. 1989. Molecular Cloning: A Laboratory Manual, 2nd ed. Cold Spring Harbor Laboratory Press, Cold Spring Harbor, NY, U.S.A.

Sleator, R. D., and Hill, C. 2001. Bacterial osmoadaptation: The role of osmolytes in bacterial stress and virulence. FEMS (Fed. Euro. Microbiol. Soc.) Microbiol. Rev. 26:49-71
Sleator, R. D., Wouters, J., Gahan, C. G., Abee, T., and Hill, C. 2001. Analysis of the role of OpuC, an osmolyte transport system, in salt tolerance and virulence potential of Listeria monocytogenes. Appl. Environ. Microbiol. 67:2692-2698.

Smid, E. J., Jansen, A. H. J., and Tuijn, C. J. 1993. Anaerobic nitrate respiration by Erwinia carotovora subsp. atroseptica during potato tuber invasion. Appl. Environ. Microbiol. 59:3648-3653.

Wyn Jones, R. G., and Storey, R. 1981. Physiology and Biochemistry of Drought Resistance in Plants. L. G. Paleg and D. Aspinall, eds. Academic Press, Sydney, New York, London. 